\title{
The nicotine inhaler was an effective and safe aid to smoking cessation
}

Hjalmarson A, Nilsson F, Sjostrom L, et al. The nicotine inhaler in smoking cessation. Arch Intern Med 1997 Aug 11/25;157:1721-8.

\section{Objective}

To evaluate the effectiveness and safety of the nicotine inhaler as an adjunct to group support in smoking cessation.

\section{Design}

1 year, randomised, double blind, placebo controlled trial.

\section{Setting}

Smoking cessation clinic at a university hospital in Göteborg, Sweden.

\section{Patients}

247 persons who were $\geqslant 20$ years of age (mean age $48 \mathrm{y}, 64 \%$ women), smoked $\geqslant 10$ cigarettes per day, smoked for $\geqslant 3$ years, and had made a previous serious attempt to quit smoking using nicotine chewing gum. Exclusion criteria included severe cardiovascular disease; pregnancy; breast feeding; use of psychotropic drugs, smokeless tobacco, or snuff; abuse of alcohol or any other drugs during the past 12 months; nicotine replacement therapy during the past 12 months; and acute medical illness. Follow up was $94 \%$.

\section{Intervention}

Participants attended support sessions lasting 45-60 minutes over 6 weeks which included behavioural modification. At the second session, participants were allocated to nicotine inhalers containing $10 \mathrm{mg}$ of nicotine and $1 \mathrm{mg}$ of menthol $(\mathrm{n}=123)$ or to placebo inhalers containing only menthol $(n=124)$. Participants were instructed to use the inhaler for 20-30 minutes, puffing more frequently than when smoking. A minimum of 4 inhalers per day were to be used on an as needed basis for the first 3 months. Participants decreased the dosage and continued use for up to 6 months.

\section{Main outcome measures}

Self reported continuous smoking abstinence verified by laboratory measurement at 2 and 3 weeks, and 3, 6, and 12 months and continued inhaler use after 3 months.

\section{Main results}

Analysis was by intention to treat. The effect of the nicotine inhaler on rates of abstinence occurred in the first 2 weeks. At 2 weeks, $55 \%$ of participants who used nicotine inhalers were abstinent compared with $35 \%$ who used placebo $(\mathrm{p}=0.02)$. In periodic evaluations after 2 weeks, there was no difference in ongoing relapse rates between the 2 groups. At 12 months, 35 participants $(28 \%)$ who used nicotine inhalers were continuously abstinent compared with 22 participants $(18 \%)$ who used placebo inhalers $(\mathrm{p}=0.05)$ (table). More participants in the nicotine group were using inhalers at 3 and 6 months compared with those in the placebo group $(33 \% v 10 \%, \mathrm{p}=0.001 ; 16 \%$ \% $3 \%$, $\mathrm{p}<0.001 ;$ respectively). Adverse effects were mild and rare, and weight gain did not differ among participants in the nicotine and placebo inhaler groups.

\section{Conclusion}

The nicotine inhaler was an effective and safe adjunct to group support in smoking cessation.

Nicotine inhalers v placebo inhalers*

\begin{tabular}{llllll}
\hline $\begin{array}{l}\text { Outcome at } 12 \\
\text { months }\end{array}$ & $\begin{array}{l}\text { Nicotine } \\
\text { inhalers } \\
\text { EER }\end{array}$ & $\begin{array}{l}\text { Placebo } \\
\text { inhalers } \\
\text { CER }\end{array}$ & $\begin{array}{l}\text { RBI } \\
(95 \% \text { CI })\end{array}$ & $\begin{array}{l}\text { ABI } \\
\mid \text { EER-CER } \mid\end{array}$ & $\begin{array}{l}\text { NNT } \\
\text { (CI) }\end{array}$ \\
\hline $\begin{array}{l}\text { Abstinence from } \\
\text { smoking }\end{array}$ & $29 \%$ & $18 \%$ & $\begin{array}{l}60 \% \\
(0.9 \text { to } 157)\end{array}$ & $11 \%$ & $\begin{array}{l}10 \\
\text { (5 to 483) }\end{array}$ \\
\hline
\end{tabular}

* Abbreviations in table defined in glossary; RBI, ABI, NNT, and CI calculated from data in article.

Source of funding: Pharmacia E Upjohn, Helsingborg, Sweden.

For article reprint: Dr A Hjalmarson, Smoking Cessation Clinic, Sahlgrenska University Hospital, 41345 Goteborg, Sweden. Fax +4631416639 .

\section{Commentary}

Tobacco related illness is a preventable cause of death. Most smokers, however, find it extremely difficult to quit because of their nicotine addiction. Current research in smoking cessation has shifted emphasis from behavioural treatment alone to interventions that include pharmacological approaches as adjunct treatments. Although clonidine, antianxiety medications, and antidepressants have received some attention, most pharmacological intervention studies focus on nicotine replacement therapy. Until recently, nicotine replacement therapy has been limited to nicotine gum or transdermal skin patches.

This well designed longitudinal study by Hjalmarson et al involved group therapy and the use of a nicotine inhaler as an adjunct treatment. Study results are sup- ported by other published studies. ${ }^{12}$ Furthermore, the use of physiological measures of nicotine consumption (the current "gold standard") greatly strengthens the validity of the results. The sample studied is important because many people who smoke are $\geqslant 40$ years of age and have ailments complicated by smoking. Because of the homogenous ethnic background of the participants, the findings may be different for other ethnic groups, pregnant women, or adolescents who smoke.

Results of the study are relevant for nurse practitioners, hospital nurses working with adults, home healthcare nurses, and community health nurses involved in secondary prevention programmes. From a practical perspective, the adverse effects (eg, cough and throat irritation) were limited, mild, and decreased over time. Nicotine inhalers provided participants with flexibility and some measure of control over the amount and timing of nicotine received. Pregnancy, chronic illness, or other health conditions must be considered before implementing nicotine replacement therapy. ${ }^{3}$ The efficacy of nicotine replacement therapy is well documented. Nicotine replacement produces lower concentrations of nicotine than cigarettes and eliminates tar and carbon monoxide; the inhaler can be used as another mode of nicotine delivery.

George Shuster, RN, DNS Associate Professor of Nursing University of Mexico Albuquerque, New Mexico, USA

1 Schneider NG, Olmstead R, Nilsson F, et al. Addiction 1996;91:1293-1306.

2 Tonnesen P, Norregaard J, Mikkelsen K, et al. JAMA 1993;269:1268-71.

3 Wewers, ME, Ahijevych KL. Annu Rev Nurs Res 1996;14:75-93. 